\title{
Study of Flowering Pattern in Setaria viridis, a Proposed Model Species for C4 Photosynthesis Research
}

\author{
Govinda Rizal, Kelvin Acebron, Reychelle Mogul, Shanta Karki, \\ Nikki Larazo, and William Paul Quick
}

C4 Rice Center, International Rice Research Institute, DAPO 7777 Metro Manila, Philippines

Correspondence should be addressed to William Paul Quick; w.p.quick@irri.org

Received 29 July 2013; Accepted 3 September 2013

Academic Editor: Karl Joseph Niklas

Copyright (C) 2013 Govinda Rizal et al. This is an open access article distributed under the Creative Commons Attribution License, which permits unrestricted use, distribution, and reproduction in any medium, provided the original work is properly cited.

Green foxtail millet (Setaria viridis) has NADP-ME type of C4 photosynthesis. Because of its short life cycle, small genome size of $\sim 515 \mathrm{Mb}$, small plant stature, high number of seed set, simple growth requirements, and wide adaptability, this diploid $(2 n=18)$ weed is proposed to be a model species for the study of $\mathrm{C} 4$ photosynthesis. It is also a representative of bioenergy grasses and a model for genetic study of invasive weeds. Despite having all traits of a model species, it is difficult to cross-pollinate because its flowering behavior is not well studied. We used time lapse digital recording to study the flowering time and pattern along a single panicle. We found that flowering in Setaria was triggered by the darkness of the night and when the temperature was lower than $35^{\circ} \mathrm{C}$. The anthesis of all the spikelets in a panicle took up-to three nights flowering from 9:30 pm to 10:00 am in the morning. Each spikelet has three phases of anthesis during which pollination occurs. A spikelet remains open for less than three hours. The pollination time for each spikelet is less than 60 minutes. Information from this study will facilitate the geneticists and plant breeders to plan for efficient crossing of Setaria.

\section{Introduction}

A common weed, green foxtail millet (Setaria viridis (L.) P. Beauv.), which belongs to family Poaceae, has gained the attention of plant scientists due mainly to its inherent $\mathrm{C} 4$ traits. Brutnell et al., (2010) proposed to make this weed a model species for C4 photosynthesis research [1], and there is a progressive support and acceptance to the proposal $[2,3]$. About 125 species are identified under genus Setaria [4], and $S$. viridis is considered the ancestral stock of this genus. Allozyme assay has shown that foxtail millet (S. italica) was the domesticated form of the S. viridis [5]. S. italica was grown as early as 6,000 years ago and was one of the oldest cultivated cereals of China [6]. Today, several species of millet belonging to the family Poaceae are widely cultivated. The major cultivated species of millet include: Pennisetum glaucum (pearl millet), Setaria italica (foxtail millet), Panicum miliaceum (proso millet), and Eleusine coracana (finger millet) [7]. The green foxtail millet is an invasive weed because of its short life span and its ability to produce seeds with long life [8]. Recently, it was reported that $S$. viridis also showed repeated evolution to herbicide resistance [9]. This finding opens a new dimension to uncover the genetic basis of the evolution of herbicide resistance.

A model plant species should have rapid regeneration cycle, small genome size, small plant size, plenty of seeds, propagation through seeds, easy to grow, and wide adaptability. It meets all these traits. A model plant should also be easy to cross pollinate to develop different kinds of mapping and breeding populations. However, the crossing of Setaria is not easy. It is important to understand the flowering pattern of $S$. viridis to use them for crossing and to generate recombinant populations.

The onset of flowering marks the transition from vegetative to reproductive phase in plants and is a necessary characteristic of bisexual plants. The objective of this research was to study the flowering pattern, flowering time, and flowering period among different Setaria accessions in general 
and the model accession A10.1 in particular that was grown in natural or close to natural environmental conditions. The mechanism of opening and closing of flowers is reviewed by van Doorn and van Meeteren [10]. Mauro-Herrera et al., (2013) had studied the genetic control of flowering in Setaria and reported three genes for flowering time in maize colocalized with the QTL they identified for Setaria [3]. The molecular-genetic studies of these populations can shed light on the mechanism of evasiveness of weeds and possibly lead to discovery of effective strategies of weed control. The temporal and spatial behaviors of opening of flowers in Setaria are reported here. This information is useful in producing crossed populations of this proposed model for the C4 species.

\section{Materials and Methods}

Fifteen accessions of $S$. viridis were obtained from North Central Regional Plant Introduction Station of the United States Department of Agriculture. These seeds were grown at Los Banos, Philippines. The accessions included one each from Afghanistan, Canada, and Chile, two each from China and Russia, three from Iran, and five from Turkey. Their accession number, region of origin and other traits are given in Tables 1 and 2.

One hundred seeds of each accession were grown in green house conditions to study the phenotypic variations. Prior to sowing, the seeds were incubated at $45^{\circ} \mathrm{C}$ for five days to break the seed dormancy. Then, the seeds were soaked in distilled water and allowed to germinate overnight at room temperature. Germinated seeds were sown into sterilized soil in pots. The sterilized soil contained $75 \%$ garden soil and 25\% river-sand and fertilized with 14-14-14 NPK at the rate of $0.25 \mathrm{~g} \cdot \mathrm{kg}^{-1}$ of soil. The seedlings grown in the pots were dipped into nutrient solution everyday to supply water and nutrients. During the growing period, the temperature ranged from 25 to $37^{\circ} \mathrm{C}$ and photosynthetically active radiation (PAR) ranged from 50 to $860 \mu \mathrm{mol} \mathrm{m}^{-2} \mathrm{~s}^{-1}$.

Germination for each accession was recorded seven days after sowing. Plant heights, number of leaves on the main tiller, and days to flowering were visually recorded, and inflorescence architectures were recorded using digital imaging. The average leaf length, leaf width, and vein density of the flag leaf and the penultimate leaves were measured. To study the phenotypic traits, twenty plants from each accession were randomly selected. The maximum width and the vein density at the widest part of the leaf and their lengths were recorded for flag and penultimate leaves. Flowering pattern and duration of flowering in accession A10.1 were studied in detail.

2.1. Setup for Time Lapse Digital Recording. The opening of spikelet and flowering along the panicle were recorded using time lapse recording USB-microscope (camera). The USB microscope was connected to laptop and, set for time lapse recording. All the instruments were set on a flat table. A thermometer and a watch were used to check temperature and time. A mirror was used to reflect the back portions of the panicle. The setup was so arranged that the front of the panicle, mirror reflection of part of the panicle away from the camera, the thermometer, and watch were within the view of the USB microscope. The magnification was $20 \mathrm{x}$ and $90 \mathrm{x}$ for whole panicle and single spikelet, respectively.

2.2. Digital Recording of Anthesis of Floret and Panicle. In accession A10.1, the panicle initiation started 18 days after sowing. Panicles of 18-20 days old plants were observed in detail. Photographs of the front and back of the panicle were taken using two USB-digital microscopes and a mirror for reflection. The two cameras were positioned at around $45^{\circ}$ angle from the left and right of the plant. The camera was set at 20x magnification. Fluorescent light was supplied to the imaging setup and turned on at night to provide clearer images. Small wrist watch and thermometer were also included in the photographs for time and temperature references. Imaging of panicle was done 24 hours for 3 days capturing the start to the completion of flowering. The camera was programmed to take picture of the panicle or floret at a rate of one snapshot per minute. Later the still images were uploaded in video at the rate of 15 images per second. The video output and individual images were saved and kept for analysis and reference (Supplementary Material 1).

Individual floret was photographed at the time of active pollen dehiscence. The digital camera was positioned close to the flower and set at 90x magnification. Florets which were ready for anthesis were imaged overnight taking one snap per minute. Pictures of selected time period encompassing from opening to closing of spikelet were used to generate time lapse video at 15 frames per second (Supplementary Material 2).

\section{Results}

Terrestrial weed S. viridis grows in almost any condition. Its tillering, panicle length, and number of seed set are greatly influenced by growing conditions, soil nutrition, light, temperature, space and water. To compare the phenotypic plasticity among different accessions, fifteen accessions of $S$. viridis (Table 1) were grown in green houses and screen houses in almost natural conditions. Seedlings were grown in plastic cups under shade or green house to protect them from damage by torrent rain. The germination recorded a week after sowing showed a wide range of variations in the seed germination percentage. The germination rate ranged from as high as $94 \%$ to as low as $25 \%$ (Table 1). Accession A10.1 had the highest germination which was $94 \%$, whereas, only one fifth of the seeds germinated in the accession PI 204730. Most of the germinated seedlings survived until flowering and maturity.

At maturity, maximum number of leaves in the main stem was six or seven in most of the accessions. One accession PI 221960 had only five leaves on the main tiller at maturity. There was distinct variation among different accession in terms of flowering time and overall phenotypes (Figure 1(a)). There was small variation within accession for the plant height, while among accessions there was very significant diversity ranging from 101 to $286 \mathrm{~cm}$ (Table 1). Two accessions 


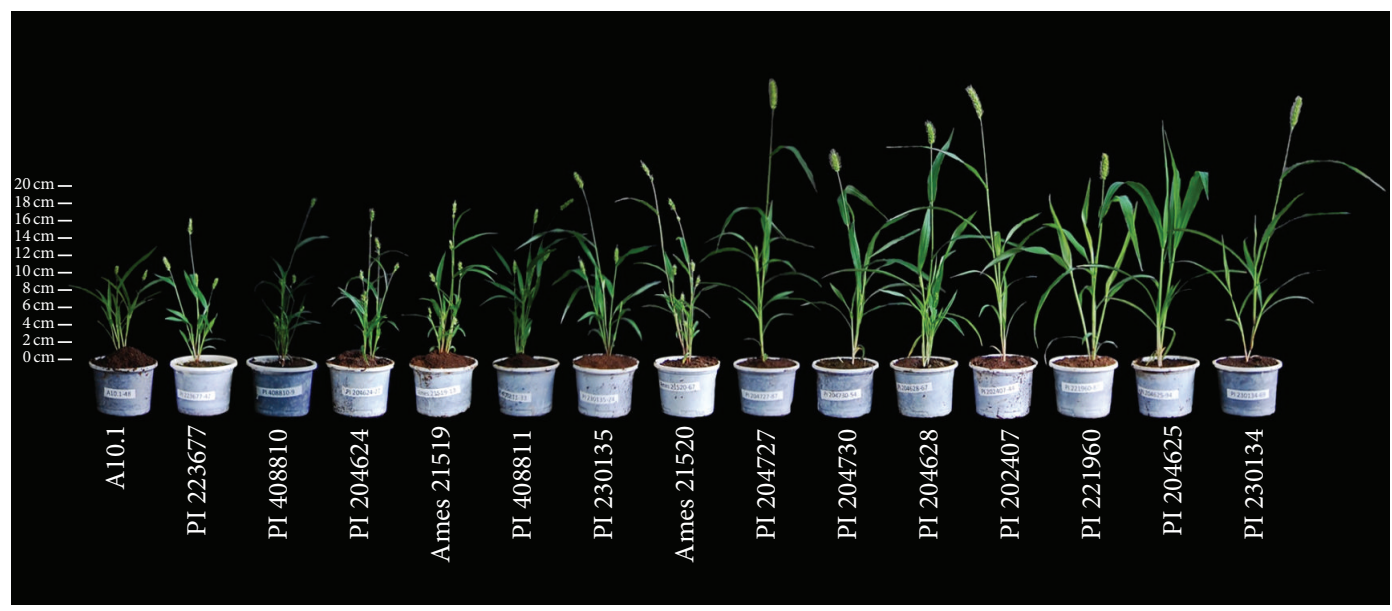

(a)

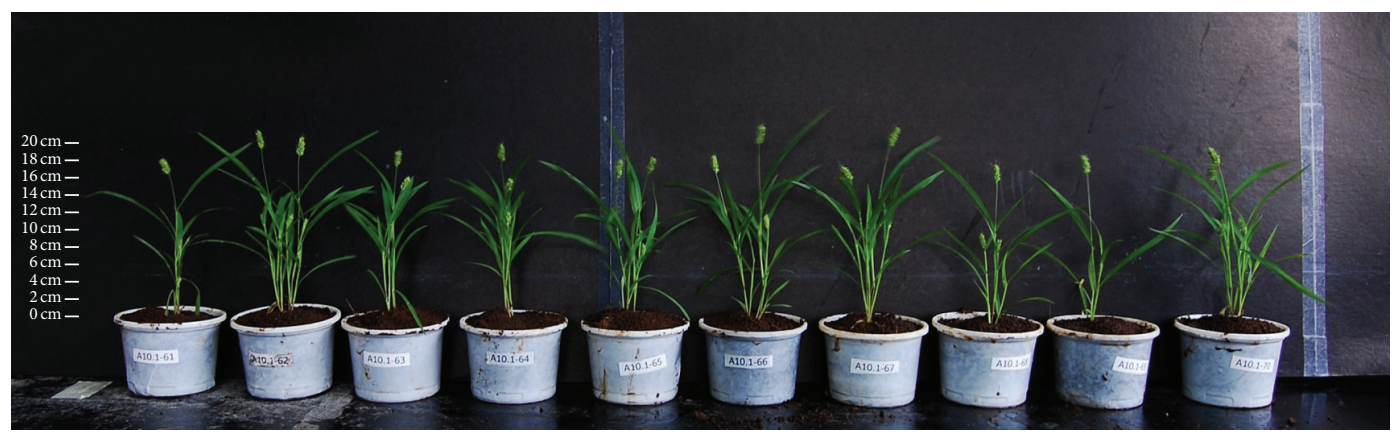

(b)

FIgURE 1: Phenotypic variations within the 15 accessions of Setaria viridis used in the experiments (a). Phenotypes of plants from the same accession (A10.1) that was used for further study of flowering pattern (b).

TABLE 1: Name of the accessions, region of origin, seed germination percentage, maximum number of leaves produced by the main tillers until maturity, average plant height achieved at the maximum growth stage, and days to 50 percent of the flowering of fifteen accessions of the Setaria viridis.

\begin{tabular}{|c|c|c|c|c|c|c|}
\hline SN & Accession & Region of origin & Germination (\%) & Highest number of leaves & $\begin{array}{l}\text { Average plant height } \\
(\mathrm{cm} \pm \mathrm{SD})\end{array}$ & $\begin{array}{c}\text { Days to flowering } \\
\text { (DAS } \pm \mathrm{SD})\end{array}$ \\
\hline 1 & A10.1 & Canada & 94 & 6 & $128 \pm 1.30$ & $19 \pm 0.10$ \\
\hline 2 & Ames 21519 & Russia & 60 & 7 & $125 \pm 2.02$ & $19 \pm 0.13$ \\
\hline 3 & Ames 21520 & Russia & 85 & 6 & $151 \pm 1.67$ & $16 \pm 0.00$ \\
\hline 4 & PI 202407 & Chile & 86 & 6 & $258 \pm 2.50$ & $23 \pm 0.13$ \\
\hline 5 & PI 204624 & Turkey & 78 & 6 & $106 \pm 1.90$ & $16 \pm 0.12$ \\
\hline 6 & PI 204625 & Turkey & 70 & 7 & $284 \pm 2.01$ & $27 \pm 0.08$ \\
\hline 7 & PI 204628 & Turkey & 24 & 6 & $242 \pm 10.53$ & $24 \pm 0.52$ \\
\hline 8 & PI 204727 & Turkey & 41 & 7 & $157 \pm 6.34$ & $21 \pm 0.40$ \\
\hline 9 & PI 204730 & Turkey & 19 & 6 & $208 \pm 13.19$ & $24 \pm 0.70$ \\
\hline 10 & PI 221960 & Afghanistan & 24 & 5 & $270 \pm 10.23$ & $25 \pm 0.31$ \\
\hline 11 & PI 223677 & Iran & 34 & 6 & $101 \pm 2.64$ & $19 \pm 0.28$ \\
\hline 12 & PI 230134 & Iran & 31 & 7 & $286 \pm 4.59$ & $24 \pm 0.31$ \\
\hline 13 & PI 230135 & Iran & 51 & 7 & $139 \pm 2.68$ & $19 \pm 0.19$ \\
\hline 14 & PI 408810 & Jilin, China & 67 & 6 & $103 \pm 2.64$ & $19 \pm 0.24$ \\
\hline 15 & PI 408811 & Shaanix, China & 47 & 6 & $136 \pm 2.33$ & $18 \pm 0.19$ \\
\hline
\end{tabular}


TABLE 2: Leaf phenotypic traits of the 15 accessions of Setaria viridis grown at Los Banos, Philippines. The width and vein density at the widest part of flag and penultimate leaves and their lengths were recorded. Twenty randomly selected plants were measured for each trait, and standard deviation (SD) is shown beside the data.

\begin{tabular}{lcccccc}
\hline \multirow{2}{*}{ Accession } & \multicolumn{2}{c}{ Leaf length $(\mathrm{mm} \pm$ SD $)$} & \multicolumn{2}{c}{ Leaf width $(\mathrm{mm} \pm$ SD) } & \multicolumn{2}{c}{ Vein density (no. of veins per mm \pm SD) } \\
& Penultimate & Flag & Penultimate & Flag & Penultimate & $11 \pm 0.11$ \\
\hline A10.1 & $71 \pm 1.08$ & $67 \pm 1.02$ & $5 \pm 0.12$ & $5 \pm 0.13$ & $10 \pm 0.09$ & $10 \pm 0.12$ \\
Ames 21519 & $54 \pm 0.81$ & $50 \pm 2.08$ & $4 \pm 0.15$ & $4 \pm 0.16$ & $9 \pm 0.10$ & $9 \pm 0.15$ \\
Ames 21520 & $55 \pm 1.20$ & $52 \pm 2.11$ & $5 \pm 0.16$ & $4 \pm 0.20$ & $9 \pm 0.16$ & $9 \pm 0.12$ \\
PI 202407 & $129 \pm 1.99$ & $121 \pm 2.46$ & $8 \pm 0.19$ & $9 \pm 0.23$ & $9 \pm 0.10$ & $9 \pm 0.13$ \\
PI 204624 & $52 \pm 1.49$ & $47 \pm 1.49$ & $4 \pm 0.16$ & $5 \pm 0.12$ & $8 \pm 0.09$ & $10 \pm 0.10$ \\
PI 204625 & $164 \pm 3.86$ & $148 \pm 2.50$ & $14 \pm 0.24$ & $14 \pm 0.29$ & $9 \pm 0.10$ & $9 \pm 0.15$ \\
PI 204628 & $115 \pm 10.73$ & $110 \pm 9.20$ & $13 \pm 4.53$ & $9 \pm 0.57$ & $9 \pm 0.16$ & $9 \pm 0.11$ \\
PI 204727 & $95 \pm 7.95$ & $94 \pm 8.17$ & $7 \pm 0.43$ & $8 \pm 0.53$ & $9 \pm 0.10$ & $9 \pm 0.13$ \\
PI 204730 & $112 \pm 8.13$ & $110 \pm 7.83$ & $8 \pm 0.42$ & $8 \pm 0.50$ & $8 \pm 0.10$ & $8 \pm 0.10$ \\
PI 221960 & $155 \pm 5.23$ & $156 \pm 6.49$ & $9 \pm 0.30$ & $12 \pm 0.43$ & $8 \pm 0.11$ & $9 \pm 0.11$ \\
PI 223677 & $42 \pm 1.53$ & $48 \pm 2.32$ & $4 \pm 0.15$ & $4 \pm 0.24$ & $8 \pm 0.11$ & $9 \pm 0.11$ \\
PI 230134 & $155 \pm 5.78$ & $140 \pm 6.54$ & $10 \pm 0.39$ & $11 \pm 0.47$ & $9 \pm 0.12$ & $8 \pm 0.10$ \\
PI 230135 & $66 \pm 3.00$ & $71 \pm 2.98$ & $5 \pm 0.22$ & $6 \pm 0.25$ & $8 \pm 0.08$ & $9 \pm 0.12$ \\
PI 408810 & $46 \pm 2.16$ & $45 \pm 3.11$ & $4 \pm 0.20$ & $4 \pm 0.23$ & $8 \pm 0.08$ & $9 \pm 0.09$ \\
PI 408811 & $52 \pm 1.41$ & $62 \pm 2.28$ & $5 \pm 0.15$ & $6 \pm 0.24$ & $8 \pm 0.06$ & \\
\hline
\end{tabular}

PI 23014 and PI 204625 were tall which had average plant height of 286 and $284 \mathrm{~cm}$, respectively. The shortest was PI 223677 which was about $100 \mathrm{~cm}$ tall (Table 1). There were very small phenotypic variations within the plants of a single accession of A10.1 in terms of matured plant height, flowering time, and number of leaves on the main tiller (Figure 1(b)).

The other phenotypic traits such as leaf width ranged from 4 to $14 \mathrm{~mm}$, leaf length ranged from 45 to $164 \mathrm{~mm}$ and the vein density ranged from 8 to 10 veins per $\mathrm{mm}$ (Table 2 ). These leaf traits varied tremendously between the accessions from different places (Table 2). All the accessions had 8 or more veins per $\mathrm{mm}$ (high vein density) in the widest part of the fully expanded leaf, a typical feature of a C4 species. Accessions from same geographical locations in Russia or China showed minor differences, those from Turkey and Iran had wide variations. These results indicate that high phenotypic plasticity exists among the different accessions.

3.1. Flowering Pattern Along the Panicle. Most accessions of S. viridis started flowering 18 days after sowing (Table 1). However, two accessions, namely, Ames 21520 and PI 204624, started flowering as early as 16 days after sowing (DAS). Accession PI 204625 was late flowering among the 15 accessions studied, which took 27 days (Table 1). The accession A10.1 flowered 19 DAS. The flowering in Setaria panicles takes place at night when it is dark and the temperature is low. Flowering started at 10:30 pm from the first spikelet at the tip of the panicle (Figure 2 and Supplementary Material 1). The temperature was $28^{\circ} \mathrm{C}$. The spikelet completely closed by 12:00 midnight. The next burst of flowering was at the center portion of the panicle around 1:00 am, when the temperature was between 26 and $27^{\circ} \mathrm{C}$. The third phase of flowering occurred in the portion between the tip and the middle. It was found that it took three nights for all spikelets in a panicle to complete flowering.

3.2. Opening and Closing of a Spikelet. Setaria has three distinct growth phases: (1) the vegetative growth phase from germination to panicle initiation; (2) the reproductive phase from panicle initiation to flowering; and (3) the ripening phase from fertilization to seed maturity. The second phase that is mainly discussed here begins two weeks after sowing in most of the accessions. The reproductive phase begins with the emergence of panicles. Length of the panicle, number of spikelets, seed set and filled seeds depend on the species, and growth conditions. The flowering usually starts from the tip and proceeds until the middle of the panicle on the first night. However, all spikelets on the cluster do not flower at the same time. Each spikelet has three phases in flowering: opening of the spikelet, the pollination, and the closing phase. These three phases complete in 3 hours in Setaria. The opening phase is initially slow, and it is rapid once started. It takes only 60 to 75 minutes for this phase. The spikelet remains open for around 60 minutes or even less. During this time, snow-white stigma blooms out of the oracle of the flower (Figure 3). Each spikelet has three anthers and a large ovary. An ovary has two styles with white branched stigmas. Three large yellow anther lobes emerge between the stigmas and shed the pollens (Figure 3 ). The anthers elongate taller than the stigma, and after a rapid desiccation they collapse mostly on the stigma. Then, the spikelets close rapidly. After closing, the vestiges of anther and stigma remain trapped outside the oracle of the spikelet. These remains of anthers, which turn from yellow to brown, are the signs that the spikelets have opened and perhaps fertilized (Figure 3 and Supplementary Material 2). The spikelets were found to open only once. The 

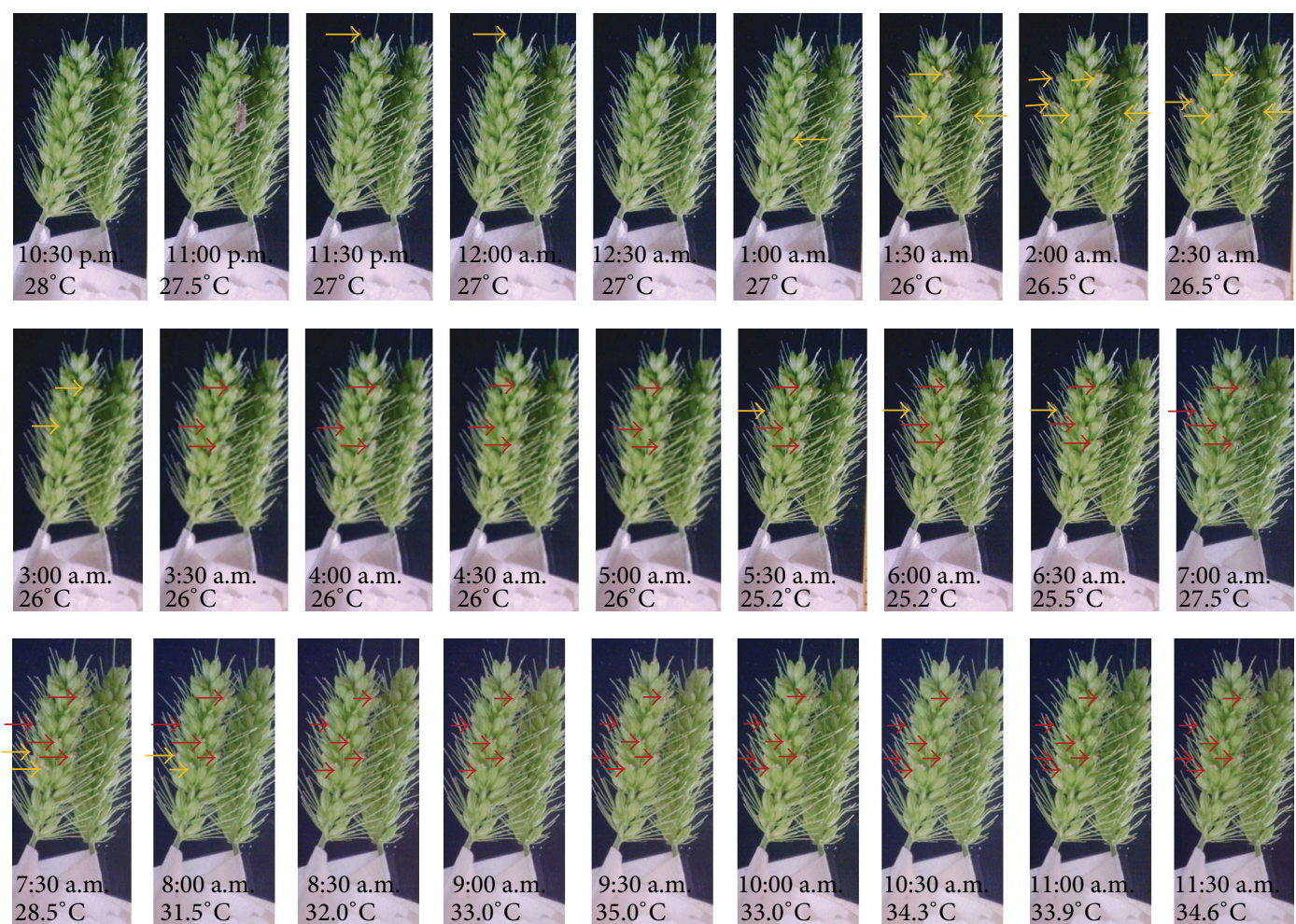

Figure 2: The time-lapse images of the flowering spikelets are shown for every 30 minutes starting from 10:30 pm to 10:00 am. Setaria viridis flowers at night when it is dark and the temperature is low. The time and the temperature recorded when the photographs were taken are mentioned in each image. The flowering spikelets are shown by yellow arrows, the vestiges of anthers and stigma after closing of spikelets are shown by red arrows, respectively. The panicle on the right side in each picture is the mirror image and shows the back part of the panicle on the left. The video of flowering is provided in Supplementary Material 1 available online at http://dx.doi.org/10.1155/2013/592429.

flowering of spikelets was random. Therefore, seed maturity is not uniform. The spikelets are seated at an angle between the rachis and bristle. Unlike in many grasses where they fall, the bristles of Setaria remain in the panicle even after the spikelets and seeds shatter off the inflorescence.

\section{Discussion}

S. viridis comprises of various accessions that originated in different parts of the world thus making it a rich source of diverse germplasm (Table 1). They differ in plant height, panicle length, flowering time, awns in the panicles, and biomass. It possesses various traits such as small plant size, short life cycle, and high number of seed production that make it a suitable model for genetic studies [11]. Its importance in research is vital as a weedy relative of the drought tolerant foxtail millet ( $S$. italica) that is grown in the drier parts of the world as a staple food crop [11]. They are cross-compatible species, and hence, they serve as very good genetic materials to identify genes related to $\mathrm{C} 4$ photosynthesis as well as for stress tolerance. Setaria being a C4 species, has high vein density, so it could also be used to identify elements controlling the vein density trait. In C4 species, the veins are closer giving them high vein density and they have kranz anatomy that helps to concentrate $\mathrm{CO}_{2}$ in the bundle sheath cells. This minimizes photorespiration thereby prevents the loss of energy [12]. Sorghum and maize have been extensively researched to identify the $\mathrm{C} 4$ specific traits. Due to their large plant sizes and long life cycles, Setaria has been a better alternative. However, the small flower sizes, nonuniform flowering along the panicle need better understanding to utilize it to create different types of mapping populations.

Effect of temperature on seed germination and phenological development of $S$. viridis have been well studied $[13,14]$. It was found that the vegetative phase was adapted to a wide range of temperature; however, the reproductive phase was very much influenced by temperature [14]. The plants produced mature seeds at temperature ranging from 23 to $35^{\circ} \mathrm{C}$ [14]. At higher temperature $44 / 35^{\circ} \mathrm{C}$, no flowering occurred [14]. Here, it was observed that the spikelets began to open when the temperature was low between 25 and $28^{\circ} \mathrm{C}$ indicating that the flowering is very much sensitive to temperature. In the morning, those spikelets which had started to open at low temperature continued flowering even when temperature increased up to $35^{\circ} \mathrm{C}$. The photoperiod sensitivity of $S$. viridis was reported elsewhere [14]. The maturity of grains also differs temporally and spatially along the panicle as they flowered on different dates.

The flowering pattern is similar among the accessions, but the days from sowing to flowering were different. Taller 

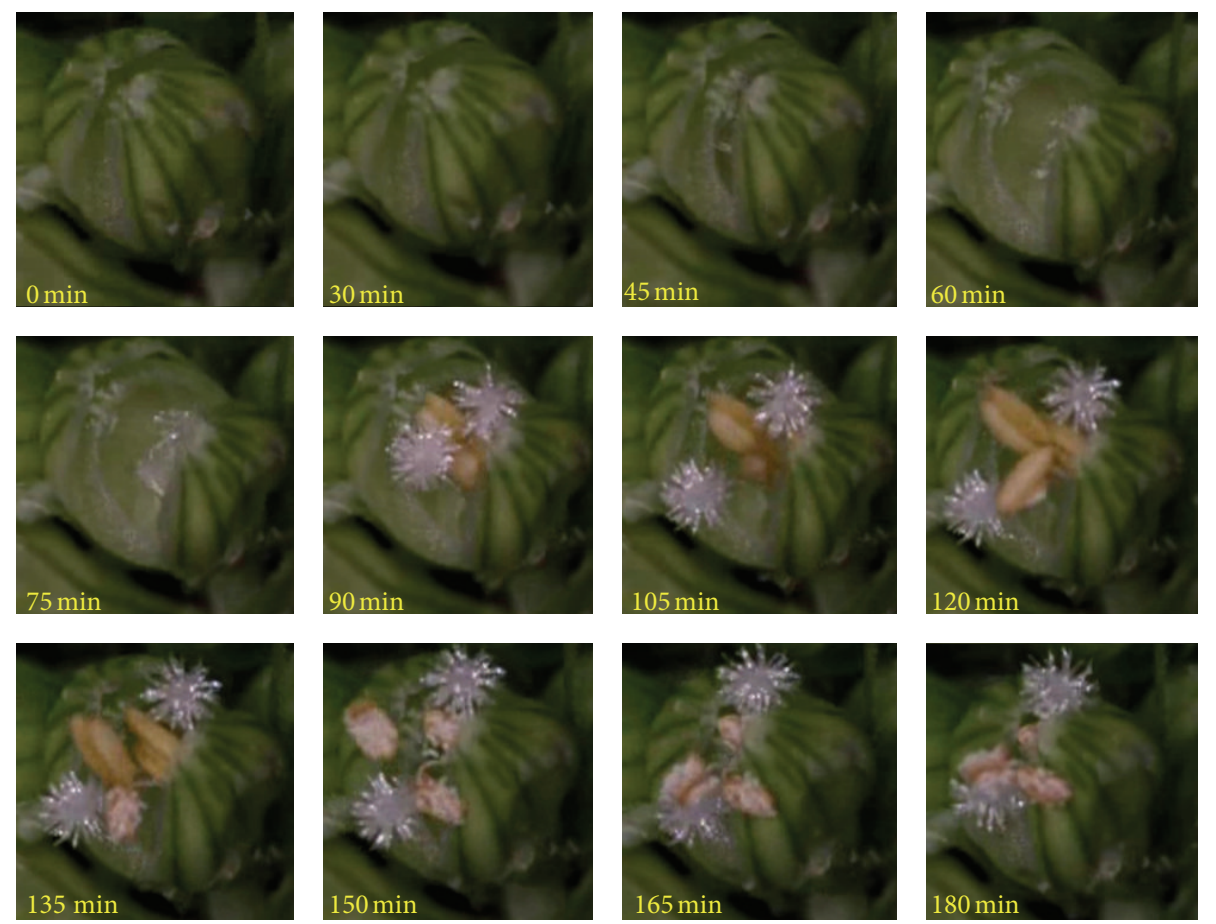

Figure 3: The time-lapse images of opening and closing of a spikelet are shown for every 30 minutes. In the first 75 minutes, the lemma and glume of the spikelet are pushed aside from inside. Then, the stigma emerges, followed by the anthers which elongate taller than stigma. The anthers dehisce and collapse on the stigma, and then, the spikelet closes. The remains of shed pollen and desiccated anther leave brown vestiges on the tip of the spikelet. The details of opening, pollination, and closing of a single spikelet are shown in the video in Supplementary Material 2.

plants with more biomass flowered later compared to the smaller plants. They are self-pollinating annual weeds, with $0.3-4 \%$ cross-pollination [15]. Flower opening in plants is a result of interplay of several factors including, but not limited to, temperature, light, humidity, endogenous rhythms, hormonal regulation, sugar status, and water balance [10] and other environmental cues. There are various strategies and mechanisms in different plants to regulate the opening and closing of their flowers [10].

It was found that the opening of Setaria spikelets was triggered by the low temperature and the darkness. Identifying the most important factors such as temperature range required for flower opening will greatly aid in artificial crossing of these species to create appropriate breeding materials. The spikelets within a panicle and even within the fascicle flowered at different time. In a panicle, the spikelets flowered for three nights. The tillers and main plants flowered on different dates, but the pattern and duration of opening of spikelets were similar. It was reported that photoperiod and temperature played key role in flowering. S. viridis grown at constant $22.5^{\circ} \mathrm{C}$ in four different photoperiods $8,12,16$, and 20 hours photoperiod flowered after 26, 28, 62, and 64 days after sowing [16]. It is difficult to manually emasculate, cross pollinate and get crossed seeds, due to nonuniform flowering. The same traits give advantage to the plant to escape stresses and ensure seed production that makes $S$. viridis a persistent weed.

Although the flowering in Setaria is nocturnal in behavior and thought to be self or wind pollinated, the insects were attracted just prior to the first anthesis. It seems Setaria flowers do release some kind of attractants to attract pollinators (Supplementary Material 1, video time from 04 to $06 \mathrm{sec}$, that is, between 10:45 and 11:30 pm). The spikelets are protected from outside by rough bristles that bar most insects from reaching the interior parts of the inflorescence. The duration of flowering depends on species, plant health, mode of pollination, resource allocation for floral maintenance, environmental factors, and so forth [17].

Availability of detailed information on the flowering habit and pattern of this important weed allows the breeders to make better utilization of the proposed model species and its rich diversity. Identification of factors for uniform anthesis such as exact temperature requirement could help in developing an appropriate crossing scheme. This could also help in discovering more genes related to flowering pattern in these important plant species.

\section{Conflict of Interests}

The authors declare that there is no conflict of interests regarding the publication of this paper.

\section{Acknowledgments}

This study was a part of the research conducted under C4 Rice Project funded by the International Rice Research Institute, Bill \& Melinda Gates Foundation, and DFID-UK. Staffs at 
C4 Rice Project are acknowledged for their technical and managerial supports.

\section{References}

[1] T. P. Brutnell, L. Wang, K. Swartwood et al., "Setaria viridis: a model for C4 photosynthesis," The Plant Cell, vol. 22, no. 8, pp. 2537-2544, 2010.

[2] J. Xu, Y. Li, X. Ma et al., "Whole transcriptome analysis using next-generation sequencing of model species Setaria viridis to support C4 photosynthesis research," Plant Molecular Biology, vol. 83, no. 1-2, pp. 77-87, 2013.

[3] M. Mauro-Herrera, X. Wang, H. Barbier, T. P. Brutnell, K. M. Devos, and A. N. Doust, "Genetic control and comparative genomic analysis of flowering time in Setaria (Poaceae)," G3: Genes, Genomes, Genetics, vol. 3, pp. 283-295, 2013.

[4] H. Darmency and J. Dekker, "Setaria," in Wild Crop Relatives: Genomic and Breeding Resources, C. Kole, Ed., pp. 275-296, 2011.

[5] R.-L. Wang, J. F. Wendel, and J. H. Dekker, "Weedy adaptation in Setaria spp. I. Isozyme analysis of genetic diversity and population genetic structure in Setaria viridis," American Journal of Botany, vol. 82, no. 3, pp. 308-317, 1995.

[6] K. C. Cheng, "Radio carbon dates from China: some initial interpretations," Current Anthropology, vol. 14, pp. 525-528, 1973.

[7] D. D. Baltensperger, "Progress with Proso, Pearl and other millets," in Trends in New Crop and New Uses, J. Janick and A. Whipkey, Eds., ASHS Press, Alexandria, VA, USA, 2002.

[8] J. Dekker, “The foxtail (Setaria) species-group," Weed Science, vol. 51, no. 5, pp. 641-656, 2003.

[9] J. L. Bennetzen, J. Schmutz, H. Wang et al., "Reference genome sequence of the model plant Setaria," Nature Biotechnology, vol. 30, no. 6, pp. 555-564, 2012.

[10] W. G. van Doorn and U. van Meeteren, "Flower opening and closure: a review," Journal of Experimental Botany, vol. 54, no. 389, pp. 1801-1812, 2003.

[11] P. Li and T. P. Brutnell, "Setaria viridis and Setaria italica, model genetic systems for the Panicoid grasses," Journal of Experimental Botany, vol. 62, no. 9, pp. 3031-3037, 2011.

[12] G. Rizal, S. Karki, V. Thakur et al., "Towards a C4 rice," Asian Journal of Cell Biology, vol. 7, no. 2, pp. 13-31, 2012.

[13] D. R. Manthey and J. D. Nalewaja, "Germination of two foxtail (Setaria) species,” Weed Technology, vol. 1, pp. 302-304, 1987.

[14] C. J. Swanton, J. Z. Huang, W. Deen, M. Tollenaar, A. Shrestha, and H. Rahimian, "Effects of temperature and photoperiod on Setaria viridis," Weed Science, vol. 47, no. 4, pp. 446-453, 1999.

[15] I. Till-Bottraud, X. Reboud, P. Brabant et al., "Outcrossing and hybridization in wild and cultivated foxtail millets: consequences for the release of transgenic crops," Theoretical and Applied Genetics, vol. 83, no. 8, pp. 940-946, 1992.

[16] M. M. Schreiber and L. R. Oliver, "Two new varieties of Setaria viridis," Weed Science, vol. 19, pp. 424-427, 1971.

[17] T.-L. Ashman and D. J. Schoen, "How long should flowers live?" Nature, vol. 371, no. 6500, pp. 788-791, 1994. 

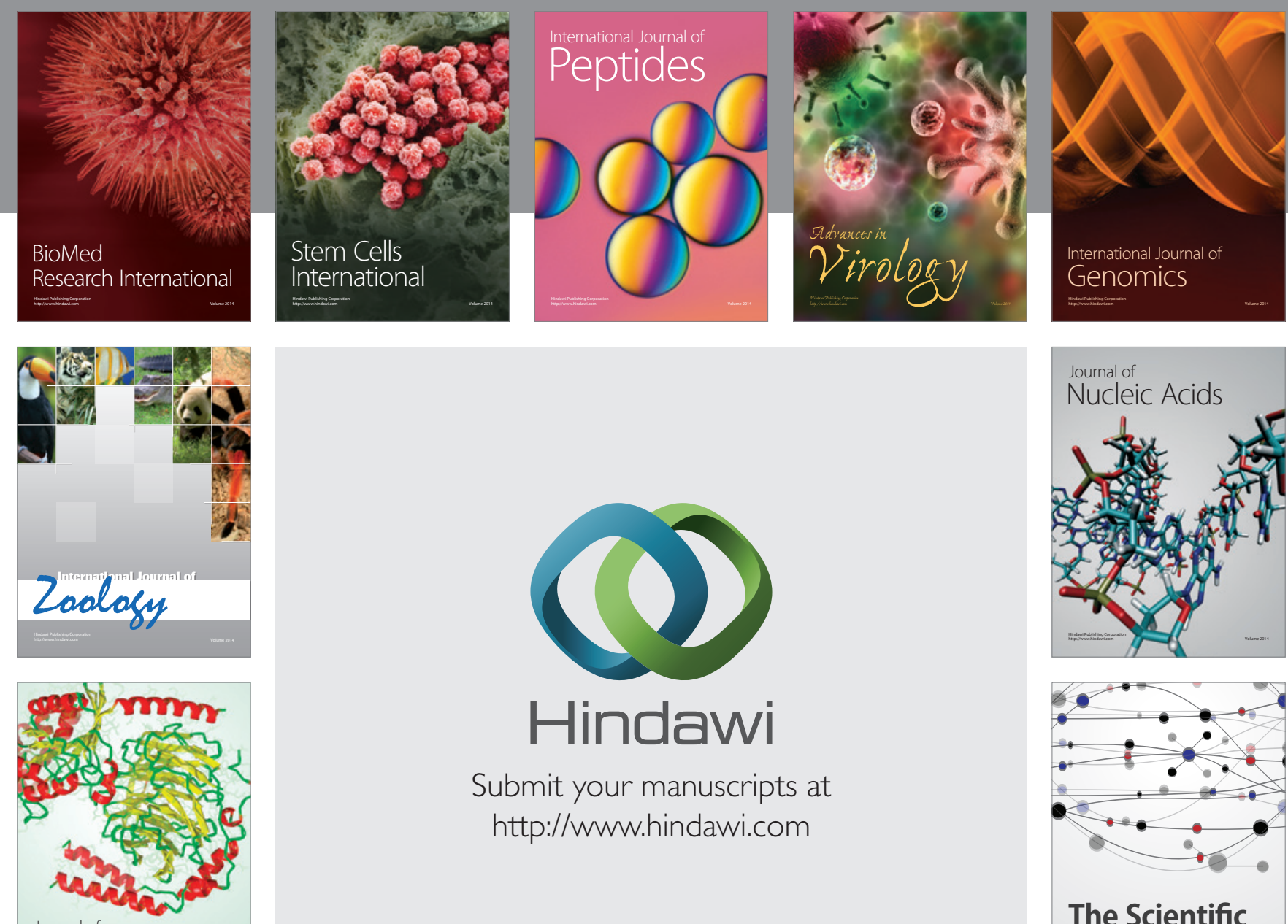

Submit your manuscripts at

http://www.hindawi.com

Journal of
Signal Transduction
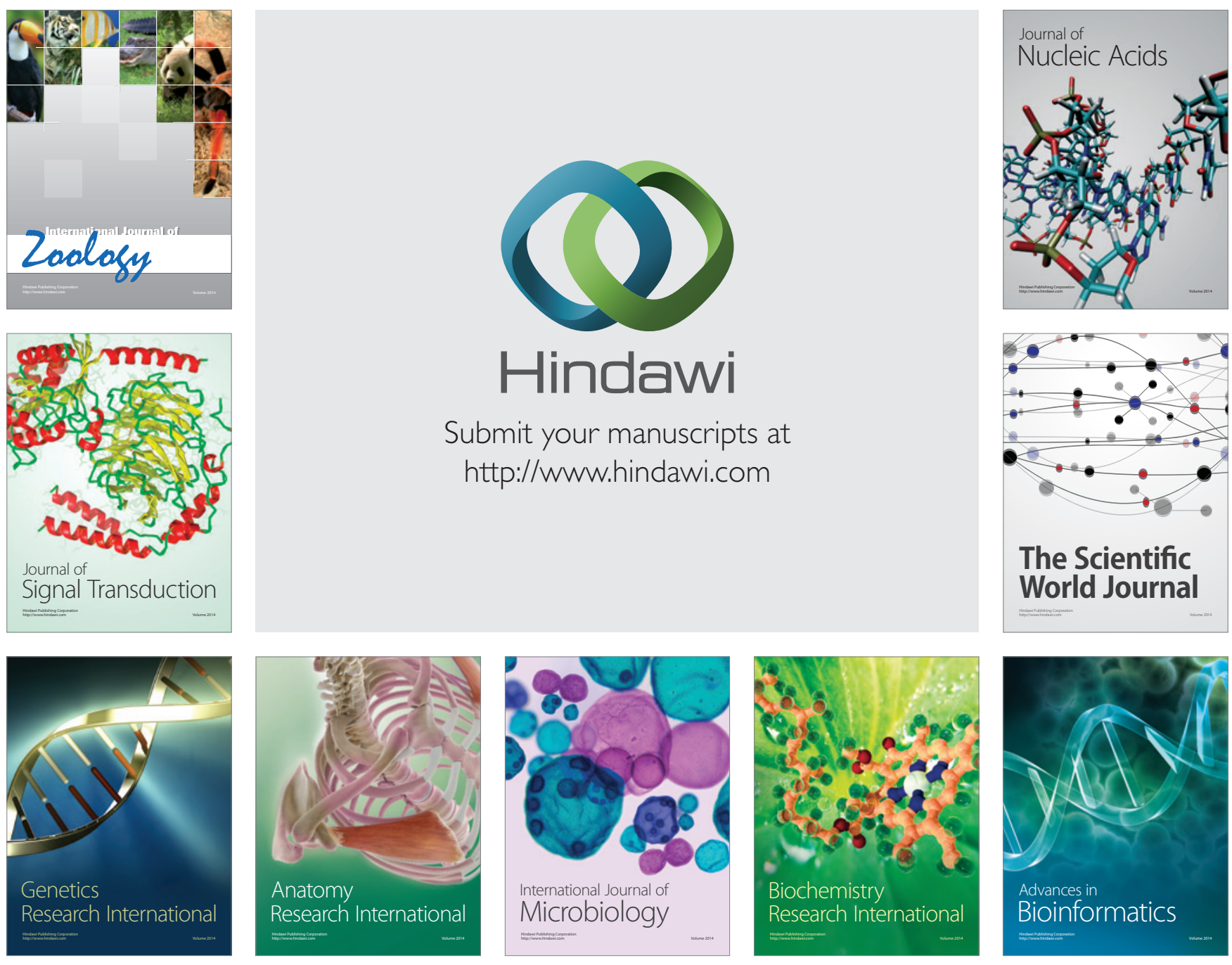

The Scientific World Journal
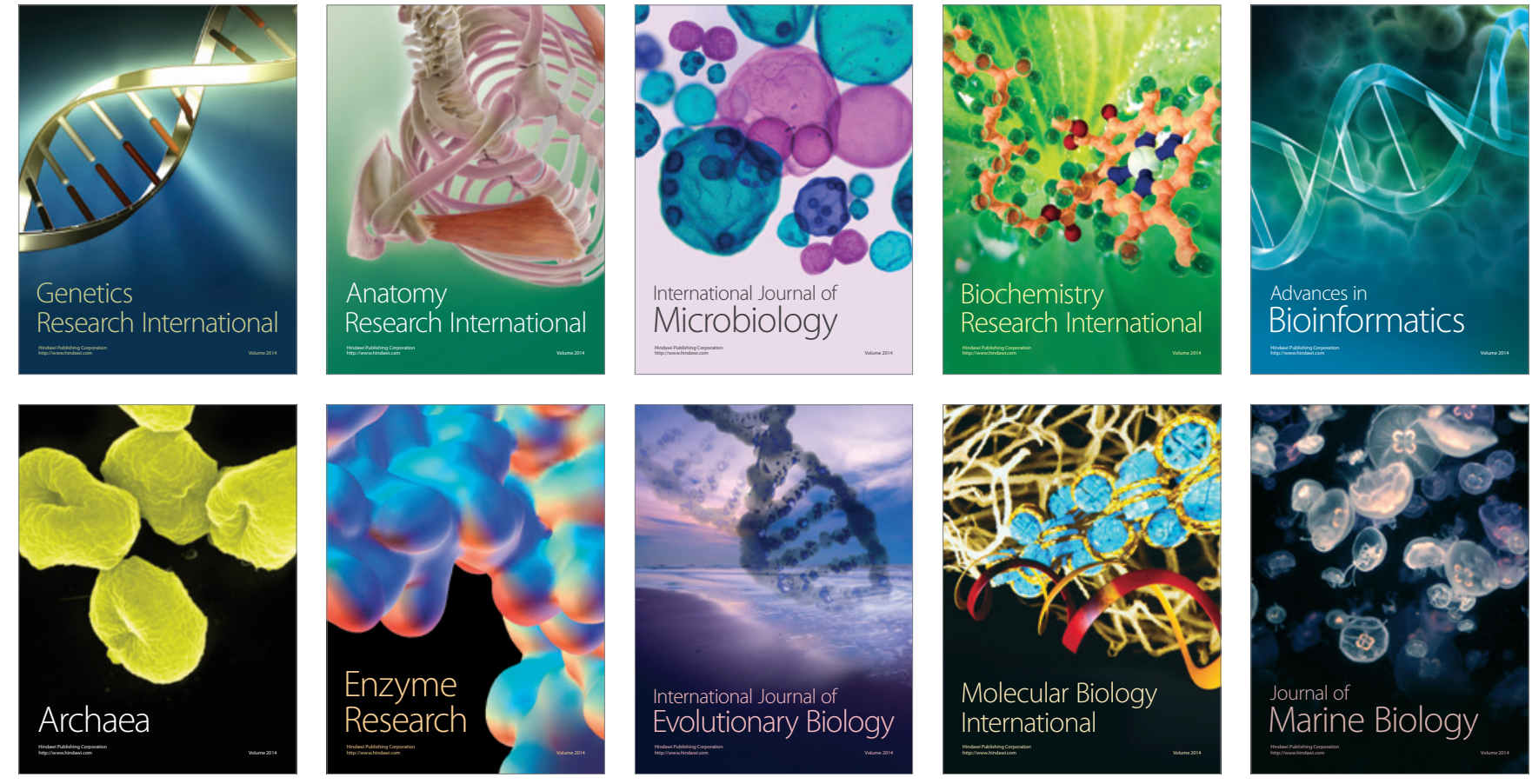